\title{
An Experimental Survey of Additives for Improving Dehydrogenation Properties of Magnesium Hydride
}

Chengshang Zhou, Zhigang Zak Fang*, and Pei Sun

Department of Metallurgical Engineering, The University of Utah, 135 South 1460 East, Room 412, Salt Lake City, Utah 84112-0114

Abstract: The use of a wide range of additives has been known as an important method for improving hydrogen storage properties of $\mathrm{MgH}_{2}$. There is a lack of a standard methodology, however, that can be used to select or compare the effectiveness of different additives. A systematic experimental survey was carried out in this study to compare a wide range of additives including transitions metals, transition metal oxides, hydrides, intermetallic compounds, and carbon materials, with respect to their effects on dehydrogenation properties of $\mathrm{MgH}_{2} \cdot \mathrm{MgH}_{2}$ with various additives were prepared by using a high-energy-high-pressure planetary ball milling method and characterized by using thermogravimetric analysis (TGA) techniques. The results showed that additives such as $\mathrm{Ti}$ and $\mathrm{V}$-based metals, hydride, and certain intermetallic compounds have strong catalytic effects. Additives such as Al, In, Sn, Si showed minor effects on the kinetics of the dehydrogenation of $\mathrm{MgH}_{2}$, while exhibiting moderate thermodynamic destabilizing effects. In combination, $\mathrm{MgH}_{2}$ with both kinetic and thermodynamic additives, such as the $\mathrm{MgH}_{2}-\mathrm{In}-\mathrm{TiMn}_{2}$ system, exhibited a drastically decreased dehydrogenation temperature.

Keywords: Magnesium hydride, hydrogen storage, kinetics, dehydrogenation temperature

\section{Corresponding author:}

*Zhigang Zak Fang, Tel: +1 (801)581-8128; Fax: +1 (801)581-4937; Email: zak.fang@utah.edu 


\section{Introduction}

Hydrogen is regarded as a future energy carrier for a cleaner environment. Due to the gaseous state of hydrogen, a practical solution for carrying hydrogen is to store it in a solid hydrogen storage material. Magnesium hydride is considered a promising hydrogen storage candidate owing to its high hydrogen storage capacity (up to $7.6 \mathrm{wt} . \%$ ), reversibility, and low costs. However, the practical use of $\mathrm{MgH}_{2}$ is limited by the fact that high temperature (generally above $300{ }^{\circ} \mathrm{C}$ ) is required to release hydrogen from $\mathrm{MgH}_{2}$ due to its thermodynamic stability and kinetic barriers.

The thermodynamic stability is one of main reasons impeding the decomposition of $\mathrm{MgH}_{2}$ at low temperature. For example, the hydrogen equilibrium pressure of $\mathrm{MgH}_{2}$ at $120^{\circ} \mathrm{C}$ is $1.0 \times 10^{-4}$ bar [1], which is hugely unfavorable for $\mathrm{MgH}_{2}$ to decompose at such a temperature. Research efforts using additive(s) to thermodynamically destabilize $\mathrm{MgH}_{2}$ have made some progresses in recent years. In particular, the use of Mg solid solution alloys (Mg-In, [1-3] Mg-Al, [4, 5] Mg-Sn [6] etc.) were demonstrated to be an effective method that could destabilize $\mathrm{MgH}_{2}$ without significant loss of the hydrogen capacity.

Kinetically, due to a slow diffusion rate of hydrogen in $\mathrm{MgH}_{2}$, its decomposition is usually sluggish. To overcome the kinetic barriers, using catalytic additives has been known to be an effective approach. Among previous reports of attempts to improve the kinetics of the dehydrogenation of $\mathrm{MgH}_{2}$, the addition of transition metals and their compounds, especially $\mathrm{Ti}$, [7-11] $\mathrm{V},[12-14]$ and $\mathrm{Nb}_{2} \mathrm{O}_{5}$ showed significant results. [15-18] Other additives, such as non- 
transition-metal elements, [1, 19-22] hydride, [8, 11] nitrides, [23, 24] carbides, [23, 25, 26]

halides, [27-32] and carbon, [33-36] also showed positive effects, as reported in the literature.

However, although considerable research has been reported in recent decades on using additives to improve the hydrogen storage properties of $\mathrm{MgH}_{2}$, [37-39] to date, it is still difficult to assess and compare the effectiveness of different additives because there are considerable discrepancies among different previous research reports, which may be attributed to different methodologies in terms of material preparation and characterization.

Furthermore, there is a constant interest in finding better or optimized catalytic additives. Therefore, a comprehensive study on the effect of additives on $\mathrm{MgH}_{2}$ is sorely needed for not only gauging the effectiveness of additives but also understanding the underlying mechanisms of their catalytic effects. In this paper, forty-nine $\mathrm{MgH}_{2}$-additive materials were synthesized and characterized to compare the effect of those additives on the dehydrogenation properties of $\mathrm{MgH}_{2}$. The additives were selected from a wide range of materials including transition metal or other elemental materials, transition metal oxides, transition metal hydrides, transition metal intermetallics, and carbon materials. Since the preparation process and the characterization were maintained throughout these experiments, the results of this work provide analogous data for guiding both experimental and mechanism studies of $\mathrm{MgH}_{2}$ with additives. 


\section{Experimental}

In order to quantitatively characterize the dehydrogenation behavior, two temperature points, namely calculated on-set dehydrogenation temperature $\left(\mathrm{T}_{\text {on-set }}\right)$ and calculated end dehydrogenation temperature $\left(\mathrm{T}_{\mathrm{end}}\right)$ were determined based on TGA curves. As illustrated in Figure 1 , the point of $\mathrm{T}_{\text {on-set }}$ was determined by the intersection of the extension line of the high plateau (the horizontal part of the curve before the dehydrogenation reaction) and the tangent of the half-dehydrided point (the mid-point in Figure 1). The point of $\mathrm{T}_{\text {end }}$ was determined by the intersection of the extension line of the low plateau (the horizontal part of the curve after the dehydrogenation reaction) and the tangent of the half-dehydriding point.

All the material handling was carried out in a glove-box filled with circulating purified argon (99.999\%), which contained less than $1 \mathrm{ppm}$ water vapor and oxygen. The sources of the raw materials used in this work, along with some notes on processing, can be found in supplementary information. Three grams of the mixtures of $\mathrm{MgH}_{2}$ and additives in various molar ratio were milled using a custom-made ultrahigh-energy-high-pressure (UHEHP) planetary ball milling machine under a 150 bar hydrogen pressure. The ball-to-powder ratio was 20:1 by volume and the milling was carried out for 4 hours at room temperature. Dehydrogenation experiments were conducted by the use of a thermal gravimetric analyzer (Shimadzu, TGA50) in which approximately $15 \mathrm{mg}$ samples were heated under $50 \mathrm{ml} / \mathrm{min}$ flowing argon to $400{ }^{\circ} \mathrm{C}$ at a heating rate of $5^{\circ} \mathrm{C} / \mathrm{min}$. The TGA instrument was placed inside the glove-box during testing. 


\section{Results and discussion}

Figure 2 summarizes the key results of all $\mathrm{MgH}_{2}$-additive samples that were prepared and tested in this work. The additives were classified into groups as: transition metals and their compounds (oxides and hydride), intermetallic compounds, III-B and IV-B group elements, and carbon materials. In addition, $\mathrm{MgH}_{2}$ with $\mathrm{LiH}$ as an additive, and three other compositions with binaryadditives (combining two additives together) i.e., $\mathrm{MgH}_{2}-\mathrm{TiH}_{2}-\mathrm{Ni}, \mathrm{MgH}_{2}-\mathrm{TiH}_{2}-\mathrm{Nb}_{2} \mathrm{O}_{5}$, and $\mathrm{MgH}_{2}-\mathrm{In}-\mathrm{TiMn}_{2}$, were synthesized and characterized. The dehydrogenation temperatures of asmilled pure $\mathrm{MgH}_{2}$ were also given as a baseline for comparison. The effectiveness of additives was evaluated by comparing their $\mathrm{T}_{\text {on-set }}$ and $\mathrm{T}_{\text {end }}$ to those of the as-milled $\mathrm{MgH}_{2}$ sample without any additives (see the lines in Figure 2).

Transition metals and their hydrides and oxides The most effective additives in this study were found in the IV-A and V-A groups. The elements from VII-A (Mn), VIII-A (Fe, Co, Ni) groups had moderate catalytic effects. For the VI A group, metal Cr presented a moderate improvement; however Mo, Mo oxides, and W oxides seemed to have no effect. Yttrium (III-A group) and Yttrium oxide showed no improvement to the kinetics. For the catalysts in metallic form, $\mathrm{Ti}$ exhibited the lowest $\mathrm{T}_{\text {on-set, }}$, followed by $\mathrm{V}, \mathrm{Mn}, \mathrm{Zr}, \mathrm{Nb}, \mathrm{Fe}, \mathrm{Ni}, \mathrm{Cr}$, and Co.

It was seen that the light elements such as $\mathrm{Ti}, \mathrm{V}$, and their compounds were more effective than heavier metals $(\mathrm{Zr}, \mathrm{Nb}, \mathrm{Ta})$ in the same groups. Another interesting observation was that the metals of $\mathrm{Ti}, \mathrm{Zr}, \mathrm{V}$, showed stronger catalytic effect than their hydrides and oxides. However, for $\mathrm{Nb}$ and $\mathrm{Ta}$ metals and compounds, the oxides performed better than their hydrides or the pure metals. 
Intermetallic compounds A set of intermetallic compounds as additives was also examined. It was found that the compounds containing $\mathrm{Ti}$ and/or $\mathrm{V}\left(\mathrm{TiMn}_{2}, \mathrm{TiNb}_{0.2}, \mathrm{TiFe}, \mathrm{TiAl}, \mathrm{Ti}_{3} \mathrm{Al}\right.$, TiVMn, TiNi, VTiCr) [7] exhibited relatively low $\mathrm{T}_{\text {on-set }}$ and $\mathrm{T}_{\text {end. }}$ It was noted that some of the compounds, such as $\mathrm{TiMn}_{2}, \mathrm{TiFe}, \mathrm{TiVMn}$, and $\mathrm{VTiCr}$, were themselves hydride-forming materials with very good reaction kinetics with hydrogen. [40] $\mathrm{LaNi}_{5}$, which is another wellknown alloy for hydrogen storage, showed moderate improvement on the dehydrogenation of $\mathrm{MgH}_{2}$. However, the AlLi compound, which contains no transition metal, showed limited effect on the dehydrogenation.

$\underline{I I I-B \text { and } I V-B \text { groups }}$ The elements in the group of post-transition metals were generally less effective than the transition metals, with two notable exceptions. The addition of Sn significantly reduced the $\mathrm{T}_{\text {on-set }}$ to $250.1{ }^{\circ} \mathrm{C}$ and the addition of $\mathrm{Al}$ reduced the $\mathrm{T}_{\text {on-set }}$ and the $\mathrm{T}_{\text {end }}$ by approximately $30{ }^{\circ} \mathrm{C}$. It has been reported that the addition of III-B and IV-B group elements including $\mathrm{Al}$, In, $\mathrm{Si}$, and $\mathrm{Sn}$ can destabilize $\mathrm{MgH}_{2}$ thermodynamically $[1,2,4,6,22,41,42]$ The destabilization reaction can be given generally as: $\mathrm{MgH}_{2}+\mathrm{xA} \rightarrow \mathrm{MgA}_{\mathrm{x}}+\mathrm{H}_{2}$. The results of this study suggest that the destabilizing of $\mathrm{MgH}_{2}$ by these III-B and IV-B elements do not necessarily result in an improvement of the kinetics of the dehydrogenation of $\mathrm{MgH}_{2}$. For example, the addition of indium was able to thermodynamically destabilize $\mathrm{MgH}_{2}$ significantly, while significant reduction of the dehydrogenation temperature was only observed when indium was used in combination with another additive, such as $\operatorname{TiMn}_{2}$. [1] 
Carbon and LiH Carbon materials that were tested in this work, regardless of the form of those carbon materials (micrometer-sized graphite, nanometer-sized carbon nanotube carbon, or mesoporous graphite), showed no improvement to the dehydrogenation kinetics. These results are consistent with previous reports. [35, 43, 44] It should be pointed out, however, that there have been intense efforts recently on using carbon materials as additives for tailoring the hydrogen storage properties of $\mathrm{MgH}_{2}$. It was reported that carbon could offer various advantages including improving cyclic stability, [36] and enhancing the thermal conductivity of the hydride. [45-47] Moreover, $\mathrm{LiH}$ as a dopant was also tested in the present work; however, it showed no improvement on the dehydrogenation, which corresponded to a recent report for $\mathrm{LiH}$ doped $\mathrm{MgH}_{2}$. [48]

Binary-additives The effects of binary-additives were studied by simultaneously milling $\mathrm{MgH}_{2}$ with two additives. It can be seen that the addition of indium and $\mathrm{TiMn}_{2}$ drastically decreased the $\mathrm{T}_{\text {on-set }}$ and the $\mathrm{T}_{\text {end }}$ to $174.2{ }^{\circ} \mathrm{C}$ and $234.2^{\circ} \mathrm{C}$, respectively. This is because of a synergetic effect of indium that provided thermodynamic destabilization and $\mathrm{TiMn}_{2}$ that has been proven as a strong kinetics enhancer. More detailed results and discussions on the thermodynamic destabilization of $\mathrm{MgH}_{2}$ by indium have been reported by the present authors elsewhere. [1] However, the binary-additives such as $\mathrm{MgH}_{2}-5 \% \mathrm{TiH}_{2}-1 \% \mathrm{Nb}_{2} \mathrm{O}_{5}$ and $\mathrm{MgH}_{2}-5 \% \mathrm{TiH}_{2}-5 \% \mathrm{Ni}$, did not show significant improvements compared to those with similar mono-additives such as $\mathrm{MgH}_{2}-5 \% \mathrm{TiH}_{2}, \mathrm{MgH}_{2}-5 \% \mathrm{Ni}$ and $\mathrm{MgH}_{2}-1 \% \mathrm{Nb}_{2} \mathrm{O}_{5}$. It can be inferred that the catalytic mechanisms of various transition metals and transition metal compounds are very similar to each other, if not exactly the same. Therefore, adding another catalyst into the system is probably similar to increasing the amount of catalyst, which is discussed in the next section. 
Content of additives In order to examine the effect of the relative content of additives on the dehydrogenation behavior of $\mathrm{MgH}_{2}$, three samples with the addition of 1,3 and $5 \mathrm{~mol} \%$ of $\mathrm{Nb}_{2} \mathrm{O}_{5}$ were prepared and their TGA weight loss analysis are shown in Figure 3. Figure 3 shows that the dehydrogenation reaction of $\mathrm{MgH}_{2}-5 \mathrm{~mol} \% \mathrm{Nb}_{2} \mathrm{O}_{5}$ occurred at a temperature that is approximately $10{ }^{\circ} \mathrm{C}$ lower compared to the sample with $1 \mathrm{~mol} \% \mathrm{Nb}_{2} \mathrm{O}_{5}$. As expected, the total weight loss (i.e. hydrogen capacity of the systems) decreased when more $\mathrm{Nb}_{2} \mathrm{O}_{5}$ additive was added to the $\mathrm{MgH}_{2}$. Also, the result showed that the $\mathrm{T}_{\text {on-set }}$ and the $\mathrm{T}_{\text {end }}$ decreased from $238.6{ }^{\circ} \mathrm{C}$ to $220.6{ }^{\circ} \mathrm{C}$, and $285.6{ }^{\circ} \mathrm{C}$ to $266.2{ }^{\circ} \mathrm{C}$, respectively, as more $\mathrm{Nb}_{2} \mathrm{O}_{5}$ was added. It was found that the $\mathrm{T}_{\text {on-set, }}$, and particularly the $\mathrm{T}_{\text {end }}$, were also affected by the amount of hydrogen that was released from the system. Despite that, the comparison of the pure $\mathrm{MgH}_{2}$ (see Figure 1) and $\mathrm{MgH}_{2}-\mathrm{Nb}_{2} \mathrm{O}_{5}$ systems showed that 1 percentage of $\mathrm{Nb}_{2} \mathrm{O}_{5}$ doping caused a significant reduction of dehydrogenation temperature (e.g. $\mathrm{T}_{\text {on-set }}$ is $323.5{ }^{\circ} \mathrm{C}$ for the as-milled $\mathrm{MgH}_{2}$ and $238.6{ }^{\circ} \mathrm{C}$ for $\mathrm{MgH}_{2}-1 \mathrm{~mol} \% \mathrm{Nb}_{2} \mathrm{O}_{5}$ ). This result indicated that increasing the quantity of the additive from 1 to $5 \mathrm{~mol} \%$ did not provide significant further benefits, while it significantly reduced the hydrogen capacity of the material. A similar trend was also reported by Choi et al., [9] in which the change of on-set dehydrogenation temperature of $\mathrm{MgH}_{2}-\mathrm{TiH}_{2}$ system was studied, varying the $\mathrm{TiH}_{2}$ content from $2 \mathrm{~mol} \%$ to $20 \mathrm{~mol} \%$.

\section{Conclusion}

In summary, forty-nine $\mathrm{MgH}_{2}$-additive compositions were examined based on the dehydrogenation temperature of $\mathrm{MgH}_{2}$ through the use of TGA analysis. Additives with strong 
catalytic effects were found to be Ti-based, V-based metals, hydride, as well as some intermetallic compounds. Elements such as $\mathrm{Al}$, In, Ge, $\mathrm{Sn}, \mathrm{Si}$ did not show significant improvement of the kinetic rates of the dehydrogenation of $\mathrm{MgH}_{2}$. Moreover, the dehydrogenation temperature was further reduced by combining $\mathrm{TiMn}_{2}$, a kinetic additive, and indium, a thermodynamic destabilizer.

\section{Acknowledgements}

This research was supported by the National Science Foundation (Grant No. 0933778) and the U.S. Department of Energy (DOE) under contract number DE-AR0000173.

\section{References}

[1] C. Zhou, Z. Z. Fang, J. Lu and X. Zhang, J. Am. Chem. Soc. 135 (2013) 10982-10985.

[2] G. Liang, J. Alloy. Compd. 370 (2004) 123-128.

[3] H. C. Zhong, H. Wang, J. W. Liu, D. L. Sun and M. Zhu, Scripta Mater. 65 (2011) 285-287.

[4] C. Zhou, Z. Z. Fang, J. Lu, X. Luo, C. Ren, P. Fan, Y. Ren and X. Zhang, J. Phys. Chem. C 118 (2014) 11526-11535.

[5] H. C. Zhong, H. Wang and L. Z. Ouyang, Int. J. Hydrogen Energy 39 (2014) 3320-3326.

[6] H. C. Zhong, H. Wang, L. Z. Ouyang and M. Zhu, J. Alloy. Compd. 509 (2011) 4268-4272.

[7] C. Zhou, Z. Z. Fang, C. Ren, J. Li and J. Lu, J. Phys. Chem. C 117 (2013) 12973-12980. 
[8] J. Lu, Y. J. Choi, Z. Z. Fang, H. Y. Sohn and E. Ro $\square$ nnebro, J. Am. Chem. Soc. 131 (2009) $15843-15852$.

[9] Y. J. Choi, J. Lu, H. Y. Sohn, Z. Z. Fang and E. Ro $\square$ nnebro, J. Phys. Chem. C 113 (2009) 19344-19350.

[10] Y. J. Choi, J. W. Choi, H. Y. Sohn, T. Ryu, K. S. Hwang and Z. Z. Fang, Int. J. Hydrogen Energy 34 (2009) 7700-7706.

[11] J. Lu, Y. J. Choi, Z. Z. Fang, H. Y. Sohn and E. Ro $\square$ nnebro, J. Am. Chem. Soc. 132 (2010) 6616-6617.

[12] H. G. Schimmel, J. Huot, L. C. Chapon, F. D. Tichelaar and F. M. Mulder, J. Am. Chem. Soc. 127 (2005) 14348-14354.

[13] S. Bouaricha, J. Huot, D. Guay and R. Schulz, Int. J. Hydrogen Energy 27 (2002) 909-913.

[14] G. Liang, J. Huot, S. Boily, A. Van Neste and R. Schulz, J. Alloy. Compd. 291 (1999) 295299.

[15] G. Barkhordarian, T. Klassen and R. Bormann, Scripta Mater. 49 (2003) 213-217.

[16] T. Ma, S. Isobe, Y. Wang, N. Hashimoto and S. Ohnuki, J. Phys. Chem. C 117 (2013) 10302-10307.

[17] N. Hanada, T. Ichikawa and H. Fujii, J. Alloy. Compd. 446-447 (2007) 67-71.

[18] K. F. Aguey-Zinsou, J. R. Ares Fernandez, T. Klassen and R. Bormann, Int. J. Hydrogen Energy 32 (2007) 2400-2407. 
[19] A. Andreasen, M. B. Sørensen, R. Burkarl, B. Møller, A. M. Molenbroek, A. S. Pedersen, J. W. Andreasen, M. M. Nielsen and T. R. Jensen, J. Alloy. Compd. 404-406 (2005) 323-326.

[20] G. Liang and R. Schulz, J. Mater. Sci. 39 (2004) 1557-1562.

[21] H. Imamura, K. Yoshihara, M. Yoo, I. Kitazawa, Y. Sakata and S. Ooshima, Int. J. Hydrogen Energy 32 (2007) 4191-4194.

[22] J. J. Vajo, F. Mertens, C. C. Ahn, R. C. Bowman and B. Fultz, J. Phys. Chem. B 108 (2004) 13977-13983.

[23] W. Oelerich, T. Klassen and R. Bormann, J. Alloy. Compd. 322 (2001) L5-L9.

[24] Y. Wang, L. Li, C. An, Y. Wang, C. Chen, L. Jiao and H. Yuan, Nanoscale 6 (2014) 66846691.

[25] I. Milanović, S. Milošević, Ž. Rašković-Lovre, N. Novaković, R. Vujasin, L. Matović, J. Francisco Fernández, C. Sánchez and J. Grbović Novaković, Ceram. Int. 39 (2013) 43994405.

[26] M. O. T. da Conceição, M. C. Brum and D. S. dos Santos, J. Alloy. Compd. 586 (2014) S101-S104.

[27] I. E. Malka, T. Czujko and J. Bystrzycki, Int. J. Hydrogen Energy 35 (2010) 1706-1712.

[28] A. Grzech, U. Lafont, P. C. M. M. Magusin and F. M. Mulder, J. Phys. Chem. C 116 (2012) 26027-26035.

[29] M. Danaie and D. Mitlin, Acta Mater. 60 (2012) 6441-6456.

[30] Y. Luo, P. Wang, L.-P. Ma and H.-M. Cheng, J. Alloy. Compd. 453 (2008) 138-142. 
[31] R. R. Shahi, A. Bhatnagar, S. K. Pandey, V. Dixit and O. N. Srivastava, Int. J. Hydrogen Energy 39 (2014) 14255-14261.

[32] M. O. T. da Conceição and D. S. dos Santos, J. Alloy. Compd. 615 (2014) S715-S718.

[33] X. Yao, C. Wu, A. Du, J. Zou, Z. Zhu, P. Wang, H. Cheng, S. Smith and G. Lu, J. Am. Chem. Soc. 129 (2007) 15650-15654.

[34] M. A. Lillo-Ródenas, Z. X. Guo, K. F. Aguey-Zinsou, D. Cazorla-Amorós and A. LinaresSolano, Carbon 46 (2008) 126-137.

[35] B. S. Amirkhiz, M. Danaie and D. Mitlin, Nanotechnology 20 (2009) 204016.

[36] B. S. Amirkhiz, M. Danaie, M. Barnes, B. Simard and D. Mitlin, J. Phys. Chem. C 114 (2010) 3265-3275.

[37] B. Sakintuna, F. Lamari-Darkrim and M. Hirscher, Int. J. Hydrogen Energy 32 (2007) 1121-1140.

[38] K.-F. Aguey-Zinsou and J.-R. Ares-Fernandez, Energ. Environ. Sci. 3 (2010) 526-543.

[39] I. P. Jain, C. Lal and A. Jain, Int. J. Hydrogen Energy 35 (2010) 5133-5144.

[40] G. Sandrock and G. Thomas, Appl. Phys. A 72 (2001) 153-155.

[41] A. Andreasen, Int. J. Hydrogen Energy 33 (2008) 7489-7497.

[42] J. C. Crivello, T. Nobuki and T. Kuji, Int. J. Hydrogen Energy 34 (2009) 1937-1943.

[43] C. X. Shang and Z. X. Guo, J. Power Sources 129 (2004) 73-80.

[44] Z. G. Huang, Z. P. Guo, A. Calka, D. Wexler and H. K. Liu, J. Alloy. Compd. 427 (2007) 94-100. 
[45] J.-H. Shim, M. Park, Y. H. Lee, S. Kim, Y. H. Im, J.-Y. Suh and Y. W. Cho, Int. J. Hydrogen Energy 39 (2014) 349-355.

[46] A. Chaise, P. de Rango, P. Marty, D. Fruchart, S. Miraglia, R. Olivès and S. Garrier, Int. J. Hydrogen Energy 34 (2009) 8589-8596.

[47] C. Pohlmann, L. Röntzsch, T. Weißgärber and B. Kieback, Int. J. Hydrogen Energy 38 (2012) 1685-1691.

[48] H. Leng, Y. Pan, Q. Li and K.-C. Chou, Int. J. Hydrogen Energy 39 (2014) 13622-13627. 


\section{Figure captions:}

Figure 1. Determination of calculated on-set temperature $\left(\mathrm{T}_{\text {on-set }}\right)$ and calculated end temperature ( $\mathrm{T}_{\text {end }}$ ) based on TGA dehydrogenation curve of as-milled $\mathrm{MgH}_{2}$.

Figure 2. Effect of various additives on dehydrogenation temperature of $\mathrm{MgH}_{2}$. The percentage of the additives to $\mathrm{MgH}_{2}$ was in molar ratio ( $\left.\mathrm{mol} \%\right)$.

Figure 3. Effect of varying amounts of additive on the TGA dehydrogenation behavior of $\mathrm{MgH}_{2}$. 


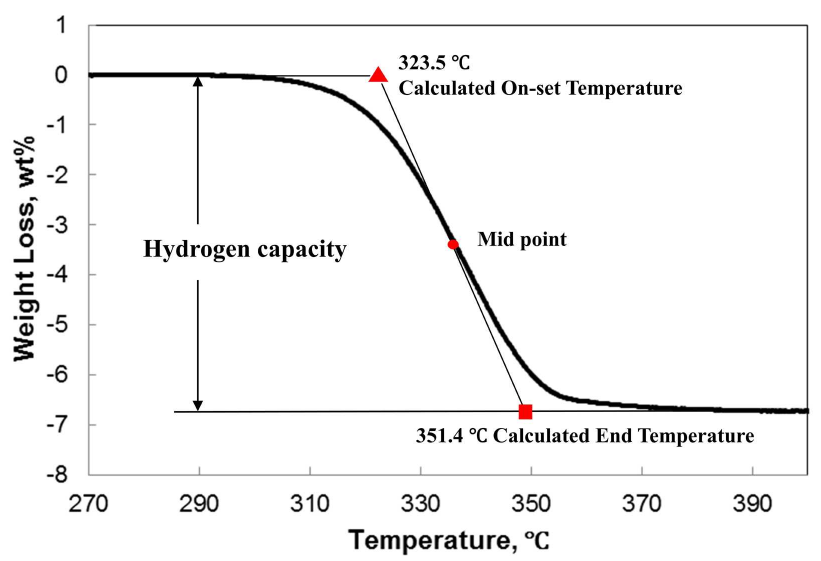




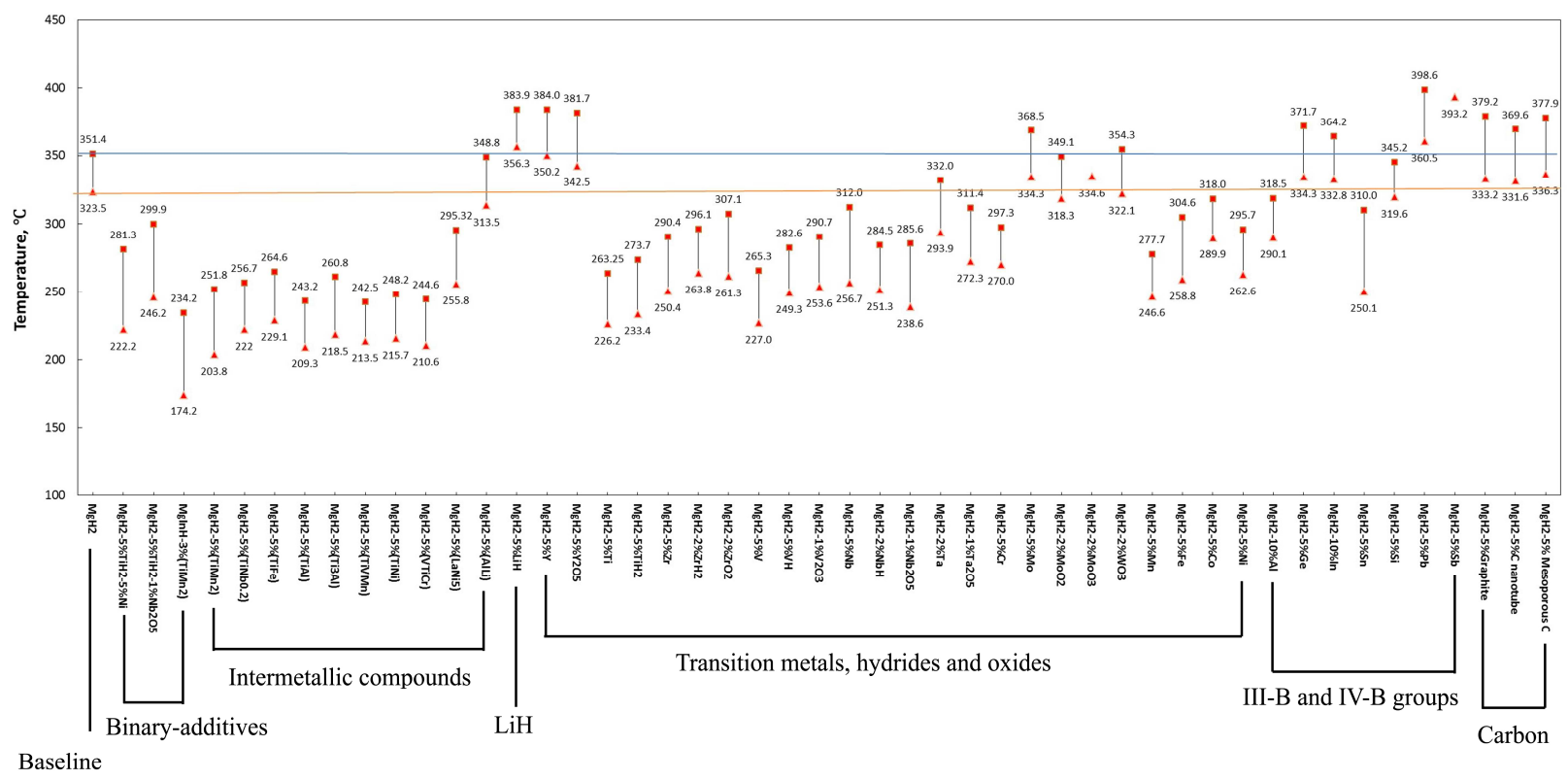




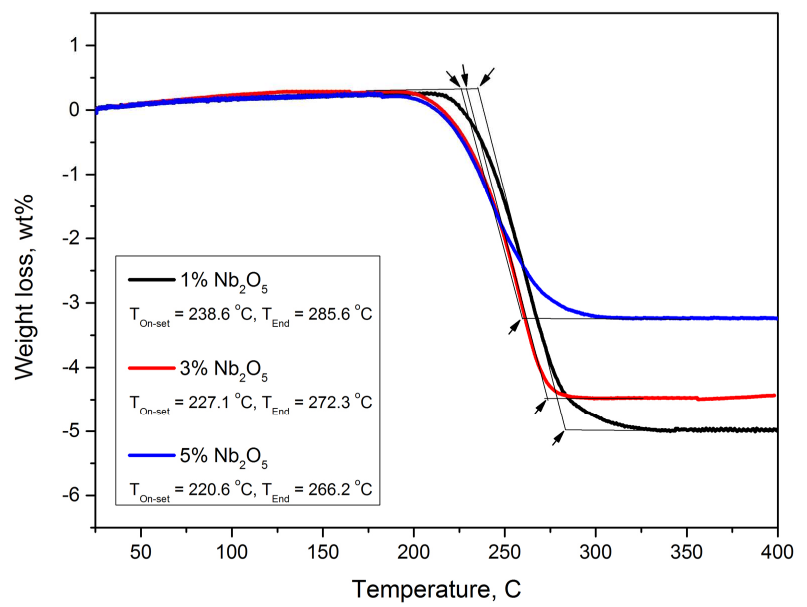




\section{Supplementary Information: An Experimental Survey of Additives for Improving Dehydrogenation Properties of Magnesium Hydride}

Chengshang Zhou, Zhigang Zak Fang*, and Pei Sun

Department of Metallurgical Engineering, The University of Utah, 135 South 1460 East, Room 412, Salt Lake City,

Utah 84112-0114

Table 1. Raw materials for this study.

\begin{tabular}{|c|c|c|}
\hline Materials & Supplier (Part No.) & Remarks \\
\hline $\mathrm{MgH}_{2}$ & Sigma-Aldrich (683043) & \\
\hline $\mathrm{Ti}_{0.98} \mathrm{Zr}_{0.02} \mathrm{~V}_{0.43} \mathrm{Fe}_{0.09} \mathrm{Cr}_{0.05} \mathrm{Mn}_{1.5}$ alloy & Sigma-Aldrich (685941) & $\begin{array}{l}\text { Pulverized by hydriding-dehydriding cycle, denoted as } \\
\mathrm{TiMn}_{2}\end{array}$ \\
\hline $\mathrm{TiNb}_{0.2}$ alloy & Custom making & Sintered \\
\hline TiFe alloy & Alfa Aesar (43500) & \\
\hline TiAl alloy & Alfa Aesar (88393) & \\
\hline $\mathrm{Ti}_{3} \mathrm{Al}$ alloy & Alfa Aesar (43101) & \\
\hline $\mathrm{TiV}_{0.62} \mathrm{Mn}_{1.5}$ alloy & GfE, Hydralloy C & $\begin{array}{l}\text { Pulverized by hydriding-dehydriding cycle, denoted as } \\
\text { TiVMn }\end{array}$ \\
\hline TiNi alloy & Alfa Aesar (88384) & \\
\hline $\mathrm{V}_{0,75} \mathrm{Ti}_{0.05} \mathrm{Cr}_{0,2}$ alloy & Custom making & Arc-melted, pulverized by hydriding denoted as $\mathrm{VTiCr}$ \\
\hline $\mathrm{LaNi}_{5}$ alloy & Sigma-Aldrich (685933) & \\
\hline AlLi alloy & Sigma-Aldrich (426490) & \\
\hline $\mathrm{LiH}$ & Alfa Aesar (41596) & \\
\hline Y & Sigma-Aldrich (261327) & \\
\hline $\mathrm{Y}_{2} \mathrm{O}_{5}$ & Sigma-Aldrich (205168) & \\
\hline $\mathrm{Ti}$ & Sigma-Aldrich (268496) & \\
\hline $\mathrm{TiH}_{2}$ & Sigma-Aldrich (209279) & \\
\hline $\mathrm{Zr}$ & Alfa Aesar (00847) & \\
\hline $\mathrm{ZrH}_{2}$ & Alfa Aesar (89484) & \\
\hline $\mathrm{ZrO}_{2}$ & Sigma-Aldrich (544760) & \\
\hline $\mathrm{V}$ & Alfa Aesar (12234) & \\
\hline $\mathrm{VH}$ & Custom making & Hydrided $\mathrm{V}$ metal powder \\
\hline $\mathrm{V}_{2} \mathrm{O}_{3}$ & Alfa Aesar (43377) & \\
\hline $\mathrm{Nb}$ & Sigma-Aldrich (262722) & \\
\hline $\mathrm{NbH}$ & Custom making & Hydrided $\mathrm{Nb}$ metal powder \\
\hline $\mathrm{Nb}_{2} \mathrm{O}_{5}$ & Sigma-Aldrich (203920) & \\
\hline $\mathrm{Ta}$ & Sigma-Aldrich (262846) & \\
\hline $\mathrm{Ta}_{2} \mathrm{O}_{5}$ & Sigma-Aldrich (204536) & \\
\hline $\mathrm{Cr}$ & Alfa Aesar (10148) & \\
\hline Mo & Alfa Aesar (10030) & \\
\hline $\mathrm{MoO}_{2}$ & Sigma-Aldrich (234761) & \\
\hline $\mathrm{MoO}_{3}$ & Sigma-Aldrich (711209) & \\
\hline $\mathrm{WO}_{3}$ & Sigma-Aldrich (550086) & \\
\hline $\mathrm{Mn}$ & Sigma-Aldrich (266132) & \\
\hline $\mathrm{Fe}$ & Alfa Aesar (10214) & \\
\hline Co & Alfa Aesar (10453) & \\
\hline $\mathrm{Ni}$ & Alfa Aesar (43214) & \\
\hline $\mathrm{Al}$ & Alfa Aesar (43891) & \\
\hline $\mathrm{Ge}$ & Alfa Aesar (10190) & \\
\hline In & Alfa Aesar (11024) & \\
\hline $\mathrm{Sn}$ & Alfa Aesar (10397) & \\
\hline $\mathrm{Si}$ & Alfa Aesar (12681) & \\
\hline $\mathrm{Pb}$ & Alfa Aesar (10223) & \\
\hline $\mathrm{Sb}$ & Alfa Aesar (10099) & \\
\hline Graphite & Alfa Aesar (40798) & \\
\hline Carbon nanotube & Alfa Aesar (44945) & \\
\hline Mesoporous Carbon & Sigma-Aldrich (699624) & \\
\hline
\end{tabular}

